\title{
Editorial: The Role of Glia in Alzheimer's Disease
}

\author{
Beatriz G. Pérez-Nievas ${ }^{1}$ and Alberto Serrano-Pozo ${ }^{2 *}$ \\ ${ }^{1}$ Department of Basic and Clinical Neuroscience, Institute of Psychiatry, King's College London, London, United Kingdom, \\ ${ }^{2}$ Department of Neurology of the Massachusetts General Hospital, Harvard Medical School, Boston, MA, United States
}

Keywords: Alzheimer's disease, amyloid plaques, astrocytes, chemokines/chemokine receptors, glia, microglia, neurofibrillary tangles (NFTs), neuroinflammation

\section{Editorial on the Research Topic}

\section{The Role of Glia in Alzheimer's Disease}

For decades, Alzheimer's disease (AD) research has focused on the two pathological hallmarks of the disease: amyloid plaques and neurofibrillary tangles. Reactive astrocytes and activated microglia decorating amyloid plaques are other long known pathological features of the AD brain (1-4), yet only recently has the role of glia in $\mathrm{AD}$ gained momentum as a research topic (5). This growing interest in glia is primarily fueled by the GWAS discovery of several risk loci in genes related to the innate immune system (6), and by the recent involvement of microglia and astrocytes in synaptic pruning and the modulation of synaptic activity in physiologic conditions (7-10). Indeed, reactive glia has been correlated with both clinical expression and progression of cognitive decline in $\mathrm{AD}(1,11)$. In the 10 articles that form this Frontiers Research Topic, now edited as an eBook, the readers will find an update on some of the most crucial aspects of astrocyte and microglia involvement in $\mathrm{AD}$ pathophysiology, as well as some of the most novel and useful tools to study both glial cell types in the context of AD.

We start with a comprehensive review on the role of reactive astrocytes in the disease,

Edited and reviewed by: Einar M. Sigurdsson,

New York University, United States

*Correspondence:

Alberto Serrano-Pozo aserrano1@mgh.harvard.edu

Specialty section: This article was submitted to Neurodegeneration, a section of the journal

Frontiers in Neurology

Received: 25 November 2018 Accepted: 14 December 2018 Published: 11 January 2019

Citation:

Pérez-Nievas BG and Serrano-Pozo A (2019) Editorial: The Role of Glia in

Alzheimer's Disease.

Front. Neurol. 9:1161. doi: 10.3389/fneur.2018.01161 highlighting the heterogeneity and complexity of astrocytes in the healthy brain, the molecular signaling pathways involved in astrocyte reaction in $\mathrm{AD}$, the phenotypic changes exhibited by reactive astrocytes in the $\mathrm{AD}$ brain, and the consequences of this astrocyte reaction with respect to plaques, tangles, neurons, and synapses (Perez-Nievas and Serrano-Pozo). Next, Garcia-Esparcia et al. compare the astrocyte reaction present in $\mathrm{AD}$ and dementia with Lewy bodies (DLB) brains by quantifying both protein and mRNA levels of several astrocyte markers such as glial fibrillary acidic protein (GFAP), excitatory amino acid transporter 2 (EAAT2/GLT-1), and aldehyde dehydrogenase 1 L1 (ALDH1L1). They observed a non-significant reduction of EAAT2/GLT-1 protein levels and a normal EAAT2/GLT-1 immunoreactivity around plaques, suggesting limited consequences of astrocyte reaction for glutamate transport in $\mathrm{AD}$.

The Frontiers Research Topic/eBook switches then gears to focus on the role of microglia in AD. Navarro et al. summarize their recent findings comparing microglia from the hippocampus of APP-overexpressing transgenic mice and human AD brains (12). They postulate that, while microglia becomes uniformly activated and pro-inflammatory in the hippocampus of mouse models of amyloid plaque deposition, a subset of microglia from the human AD hippocampus might be dysfunctional and exhibit an attenuated inflammatory response, and even degenerate due to the toxicity mediated by soluble tau oligomers. Zhou et al. review the physiology of triggering receptor expressed on myeloid cell 2 (TREM2) and its implication in amyloid plaque and tangle formation from studies on Trem 2 deficient AD mouse models. They also review 
their recent finding that TREM2 enhances microglial metabolism through the mammalian target of rapamycin (mTOR) pathway (13), suggesting that the $\mathrm{AD}$-linked TREM2 variants $(14,15)$ can modulate $\mathrm{AD}$ pathogenesis through an aberrant microglial metabolism. Guedes et al. review the contributions of microglial and monocyte chemokines and their receptors (CCL2/CCR2, CX3CL1/CX3CR1, CCL5/CCR5, CXCL10/CXCR3, and CXCL1/CXCR2) to amyloid and tau pathologies. Thei et al. contribute with a review of the ion channels expressed by homeostatic microglia, their potential disruption in activated microglia in $\mathrm{AD}$, and how human inducible pluripotent stem cell (hiPSC)-derived microglia could be a better tool than primary microglial cultures to elucidate the role of these ion channels. And, finally, Chun et al. summarize their experience with novel in vitro approaches to study glia, including microfluidic devices with human microglia exposed to $A \beta$ to investigate microglial chemotaxis (16), and a $3 \mathrm{D}$ organotypic $\mathrm{AD}$ brain model (17) consisting of culturing neurons, microglia and astrocytes from immortalized human $\mathrm{AD}$ neural progenitor cells or hiPSC-derived neural progenitor cells in a $3 \mathrm{D}$ microfluidic platform.

Lastly, the Frontiers Research Topic/eBook deals with the imaging methods available to study reactive glia. Edison et al. review the literature on PET imaging of reactive glia in both human $\mathrm{AD}$ subjects and $\mathrm{AD}$ mouse models. PET radiotracers targeting the translocator protein of $18 \mathrm{KDa}$ (TSPO) have been widely used for almost two decades to image activated microglia in vivo (18), whereas $\left[{ }^{11} \mathrm{C}\right]$ deuterium-L-deprenyl $\left(\left[{ }^{11} \mathrm{C}\right] \mathrm{DED}\right)$ an irreversible inhibitor of monoamine oxidase $\mathrm{B}$-has recently been introduced to image reactive astrocytes (19), which are known to up-regulate this enzyme (20). Hierro-Bujalance et al. provide an update on the methodology of intravital multiphoton microscopy and its applications to image microglia in vivo in $\mathrm{AD}$ mouse models. Examples of key observations using this technique include the microglia chemotaxis toward amyloid

\section{REFERENCES}

1. Serrano-Pozo A, Mielke ML, Gómez-Isla T, Betensky RA, Growdon JH, Frosch MP, et al. Reactive glia not only associates with plaques but also parallels tangles in Alzheimer's disease. Am J Pathol. (2011) 179:1373-84. doi: 10.1016/j.ajpath.2011.05.047

2. Serrano-Pozo A, Gómez-Isla T, Growdon JH, Frosch MP, Hyman BT. A phenotypic change but not proliferation underlies glial responses in Alzheimer disease. Am J Pathol. (2013) 182:2332-44. doi: 10.1016/j.ajpath.2013.02.031

3. Serrano-Pozo A, Muzikansky A, Gómez-Isla T, Growdon JH, Betensky RA, Frosch MP, et al. Differential relationships of reactive astrocytes and microglia to fibrillar amyloid deposits in Alzheimer disease. J Neuropathol Exp Neurol. (2013) 72:462-71. doi: 10.1097/NEN.0b013e3182933788

4. Serrano-Pozo A, Betensky RA, Frosch MP, Hyman BT. Plaque-associated local toxicity increases over the clinical course of Alzheimer disease. Am J Pathol. (2016) 186:375-84. doi: 10.1016/j.ajpath.2015.10.010

5. Serrano-Pozo A, Aldridge GM, Zhang Q. Four Decades of Research in Alzheimer's disease (1975-2014): a bibliometric and scientometric analysis. $J$ Alzheimers Dis. (2017) 59:763-83. doi: 10.3233/JAD-170184

6. Lambert JC, Ibrahim-Verbaas CA, Harold D, Naj AC, Sims R, Bellenguez C, et al. Meta-analysis of 74,046 individuals identifies 11 new susceptibility loci for Alzheimer's disease. Nat Genet. (2013) 45:1452-8. doi: 10.1038/ng.2802 plaques after these are formed, its limited role in controlling plaque growth, and its activation and participation in plaque clearance upon treatment with anti- $\mathrm{A} \beta$ antibodies. Kelly et al. address the current applications of intravital multiphoton microscopy to image astrocytes in vivo in $\mathrm{AD}$ mouse models. These include, among others, the topical use of the dye sulforhodamine-101 (SR-101) to study astrocyte morphology and distribution (21), and the virally-mediated expression of genetically-encoded calcium indicators to track astrocyte calcium dynamics as a functional read-out (e.g., calcium waves at both intracellular and network scales) (22). Practical examples of these functional studies include the investigation of spontaneous calcium transients as a function of proximity to amyloid plaques and cerebral amyloid angiopathy (CAA)-affected vessels, and the examination of evoked calcium transients in paradigms of functional hyperemia.

In summary, although acknowledging that the topic of glial cells in $\mathrm{AD}$ is a rapidly evolving field, we believe that the present Frontiers Research Topic/eBook will provide the interested readers with the most recent developments on the role of reactive astrocytes and activated microglia to $\mathrm{AD}$ pathophysiology, and the latest technical advances to study and image these glial cells in vitro and in vivo in $\mathrm{AD}$ patients and mouse models.

\section{AUTHOR CONTRIBUTIONS}

All authors listed have made a substantial, direct and intellectual contribution to the work, and approved it for publication.

\section{FUNDING}

This work was supported by Alzheimer's Research UK (ARUKRF2014-2) to BP-N, National Institute of Neurological Disorders and Stroke (NINDS R25NS065743) to AS-P, and Alzheimer's Association (AACF-17-524184) to AS-P.
7. Christopherson KS, Ullian EM, Stokes CCA, Mullowney CE, Hell JW, Agah A, et al. Thrombospondins are astrocyte-secreted proteins that promote CNS synaptogenesis. Cell (2005) 120:421-33. doi: 10.1016/j.cell.2004.12.020

8. Stevens B, Allen NJ, Vazquez LE, Howell GR, Christopherson KS, Nouri N, et al. The classical complement cascade mediates CNS synapse elimination. Cell (2007) 131:1164-78. doi: 10.1016/j.cell.2007.10.036

9. Allen NJ, Bennett ML, Foo LC, Wang GX, Chakraborty C, Smith SJ, et al. Astrocyte glypicans 4 and 6 promote formation of excitatory synapses via GluA1 AMPA receptors. Nature (2012) 486:410-4. doi: 10.1038/nature11059

10. Chung W-S, Clarke LE, Wang GX, Stafford BK, Sher A, Chakraborty C, et al. Astrocytes mediate synapse elimination through MEGF10 and MERTK pathways. Nature (2013) 504:394-400. doi: 10.1038/nature12776

11. Perez-Nievas BG, Stein TD, Tai H-C, Dols-Icardo O, Scotton TC, Barroeta-Espar I, et al. Dissecting phenotypic traits linked to human resilience to Alzheimer's pathology. Brain J Neurol. (2013) 136:2510-26. doi: 10.1093/brain/awt171

12. Sanchez-Mejias E, Navarro V, Jimenez S, Sanchez-Mico M, Sanchez-Varo R, Nuñez-Diaz C, et al. Soluble phospho-tau from Alzheimer's disease hippocampus drives microglial degeneration. Acta Neuropathol. (2016) 132:897-916. doi: 10.1007/s00401-016-1630-5

13. Ulland TK, Song WM, Huang SC-C, Ulrich JD, Sergushichev A, Beatty WL, et al. TREM2 maintains microglial metabolic fitness in Alzheimer's disease. Cell (2017) 170:649-63.e13. doi: 10.1016/j.cell.2017.07.023 
14. Guerreiro R, Wojtas A, Bras J, Carrasquillo M, Rogaeva E, Majounie E, et al. TREM2 variants in Alzheimer's disease. N Engl J Med. (2013) 368:117-27. doi: 10.1056/NEJMoa1211851

15. Jonsson T, Stefansson H, Steinberg S, Jonsdottir I, Jonsson PV, Snaedal J, et al. Variant of TREM2 associated with the risk of Alzheimer's disease. $N$ Engl J Med. (2013) 368:107-16. doi: 10.1056/NEJMoa1211103

16. Cho $\mathrm{H}$, Hashimoto $\mathrm{T}$, Wong $\mathrm{E}$, Hori $\mathrm{Y}$, Wood LB, Zhao L, et al. Microfluidic chemotaxis platform for differentiating the roles of soluble and bound amyloid- $\beta$ on microglial accumulation. Sci Rep. (2013) 3:1823. doi: $10.1038 /$ srep01823

17. Park J, Wetzel I, Marriott I, Dréau D, D'Avanzo C, Kim DY, et al. A 3D human triculture system modeling neurodegeneration and neuroinflammation in Alzheimer's disease. Nat Neurosci. (2018) 21:941-51. doi: 10.1038/s41593-018-0175-4

18. Cagnin A, Brooks DJ, Kennedy AM, Gunn RN, Myers R, Turkheimer FE, et al. In-vivo measurement of activated microglia in dementia. Lancet Lond Engl. (2001) 358:461-7. doi: 10.1016/S0140-6736(01)05625-2

19. Rodriguez-Vieitez E, Saint-Aubert L, Carter SF, Almkvist O, Farid K, Schöll $\mathrm{M}$, et al. Diverging longitudinal changes in astrocytosis and amyloid PET in autosomal dominant Alzheimer's disease. Brain J Neurol. (2016) 139:922-36. doi: 10.1093/brain/awv404
20. Nakamura S, Kawamata T, Akiguchi I, Kameyama M, Nakamura N, Kimura $\mathrm{H}$. Expression of monoamine oxidase B activity in astrocytes of senile plaques. Acta Neuropathol. (1990) 80:419-25.

21. Nimmerjahn A, Kirchhoff F, Kerr JND, Helmchen F. Sulforhodamine 101 as a specific marker of astroglia in the neocortex in vivo. Nat Methods (2004) 1:31-7. doi: 10.1038/nmeth706

22. Kuchibhotla KV, Lattarulo CR, Hyman BT, Bacskai BJ. Synchronous hyperactivity and intercellular calcium waves in astrocytes in Alzheimer mice. Science (2009) 323:1211-5. doi: 10.1126/science.1169096

Conflict of Interest Statement: The authors declare that the research was conducted in the absence of any commercial or financial relationships that could be construed as a potential conflict of interest.

Copyright (C) 2019 Pérez-Nievas and Serrano-Pozo. This is an open-access article distributed under the terms of the Creative Commons Attribution License (CC BY). The use, distribution or reproduction in other forums is permitted, provided the original author(s) and the copyright owner(s) are credited and that the original publication in this journal is cited, in accordance with accepted academic practice. No use, distribution or reproduction is permitted which does not comply with these terms. 